\title{
Mechanical Properties and Microstructural Evolution of CuZn Alloys via Pre-Torsional Deformation
}

\author{
Ji Gu ${ }^{a}$, Song Ni ${ }^{a}$, Min Song ${ }^{a *}$ *i) \\ ${ }^{a}$ State Key Laboratory of Powder Metallurgy, Central South University, Changsha 410083, P.R. China
}

Received: June 18, 2018; Revised: March 11, 2019; Accepted: March 25, 2019

\begin{abstract}
Mechanical properties and microstructural evolution of $\mathrm{Cu}-10 \mathrm{wt} . \% \mathrm{Zn}$ and $\mathrm{Cu}-30 \mathrm{wt} . \% \mathrm{Zn}$ alloys after pre-torsional deformation have been investigated in this study. The results indicated that pretorsional deformation can significantly enhance the strength of both $\mathrm{Cu}-10 \mathrm{wt} . \% \mathrm{Zn}$ and $\mathrm{Cu}-30 \mathrm{wt} . \% \mathrm{Zn}$ alloys without changing their shape and size, but with the sacrifice of the ductility. The pre-torsion deformation can introduce gradient hardness and microstructures along the radial direction, with the microstructures along the radial direction in $\mathrm{Cu}-30 \mathrm{wt} . \% \mathrm{Zn}$ alloy being "dislocations $\rightarrow$ stacking faults $\rightarrow$ twins (low density)". The stacking fault energy affects significantly the microstructure along the radial direction.
\end{abstract}

Keywords: $\mathrm{Cu}$-Zn alloys, pre-torsional deformation, mechanical properties, microstructure.

\section{Introduction}

Plastic deformation is an effective technique for producing bulk metals with tailoring properties ${ }^{1}$. Recently, severe plastic deformation (SPD) techniques have attracted much attention due to their ability to fabricate bulk ultrafine grained (UFG) and/or nanocrystalline materials with an average grain size less than $1 \mu \mathrm{m}^{2}$. Several SPD techniques, including equal channel angular pressing (ECAP), high pressure torsion (HPT), multidirectional forging (MDF) and accumulative roll bonding (ARB), are available for applying high strains on bulk materials ${ }^{3}$. Amongst all SPD techniques, HPT is the most convenient and effective technique where a thin disc or ring is placed between two massive anvils under a high pressure and intense shear strain is introduced by rotating the two anvils with respect to each other ${ }^{4-6}$. Materials treated by HPT usually have high strength but relatively low ductility at ambient temperature ${ }^{7-9}$. In addition, the dimensions of the samples prepared by SPD are too small, which limit their wide applications in modern industry.

Recently, improving the mechanical properties of structural metals via pre-tension ${ }^{10}$, pre-compression ${ }^{11}$, pre-rolling ${ }^{12}$ and surface mechanical attrition treatment (SMAT) ${ }^{13}$ have been extensively reported. It is commonly accepted that pre-deformation greatly affects the deformation behaviors of metals. Compared to the other deformation modes, pre-torsion with only pure shear strain doesn't induce any change in the sample's shape and size. Thus, simple torsional deformation has been widely reported to tailoring the properties of metals recently ${ }^{14-19}$. Pre-torsional treatment of a TWIP steel resulted in the formation of gradient nanotwin density that successfully overcame the strength-ductility trade-off dilemma ${ }^{16}$. While, pre-torsional treatment of copper and a magnesium alloy did not introduce gradient nanotwin

*e-mail: msong@csu.edu.cn structures but produced gradient grain size and dislocation substructures that improved the tensile strength but with the ductility trade-off ${ }^{17,18}$.

It is clear from the above-mentioned studies that pretorsional treatment significantly affects the strength and ductility, which are highly dependent on the processing materials. Stacking fault energy (SFE) is an important factor affecting the deformation mechanisms of materials. Reducing SFE significantly increases the propensity of deformation twinning, which increases the strain hardening rate, dislocation storage capacity, and ductility ${ }^{20-22}$. In this paper, $\mathrm{Cu}-10 \mathrm{wt} . \% \mathrm{Zn}$ and Cu-30wt.\%Zn alloys with different SFEs $\left(\sim 35 \mathrm{~mJ} / \mathrm{m}^{2}\right.$ and $~$ $13 \mathrm{~mJ} / \mathrm{m}^{2}$, respectively ${ }^{23}$ ) were pre-torsional deformed, and the effects of pre-torsional deformation on the mechanical properties and microstructural evolution of the alloys were investigated.

\section{Experimental}

Raw materials of $\mathrm{Cu}-10 \mathrm{wt} . \% \mathrm{Zn}$ and $\mathrm{Cu}-30 \mathrm{wt} . \% \mathrm{Zn}$ alloys were bought from market. These two alloys are single phase solid solutions without any precipitate phase ${ }^{24}$. Dog-boneshaped specimens with a gauge size of $\Phi 6 \mathrm{~mm} \times 20 \mathrm{~mm}$ were fabricated by wire electrical discharge machine for the free-end torsional deformation. The torsional treatment was carried out with a constant rate of $1 \mathrm{rpm}$ for $0^{\circ}, 45^{\circ}, 90^{\circ}$, $180^{\circ}$ and $360^{\circ}$, respectively, using MTS 858 Mini Bionix II testing machine. The specimens in this paper were labeled as "composition-torsional angle". The composition and torsional angle of different specimens and the corresponding specimen names were listed in Table 1 . The tensile experiments were conducted using an Instron 3369 testing system with a tensile rate of $\sim 10^{-5} \mathrm{~s}^{-1}$. The hardness was measured along the radial direction using an FEI-VM50 PC Vickers hardness testing machine, with the indentation load and dwelling time being 
Table 1. The composition, torsional angle and corresponding specimen names of different specimens.

\begin{tabular}{lcc}
\hline Composition & Torsional angle $\left(^{\circ}\right)$ & Specimens name \\
\hline & 0 & Cu10Zn-0 \\
Cu-10wt.\%Zn & 45 & Cu10Zn-45 \\
& 90 & Cu10Zn-90 \\
& 180 & Cu10Zn-180 \\
& 360 & Cu10Zn-360 \\
& 0 & Cu30Zn-0 \\
Cu-30wt.\%Zn & 45 & Cu30Zn-45 \\
& 90 & Cu30Zn-90 \\
& 180 & Cu30Zn-180 \\
& 360 & Cu30Zn-360 \\
\hline
\end{tabular}

$10 \mathrm{~g}$ and $15 \mathrm{~s}$, respectively. The hardness at each position along the radial direction was averaged from 10 independent measurements. The pre-torsional treated specimens were cut using a low speed diamond saw for microstructural characterization. The microstructures of the specimens were examined from the diametrical cross-section by a JEOL $2100 \mathrm{~F}$ transmission electron microscope (TEM) with an accelerating voltage of $200 \mathrm{kV}$. The TEM investigations were taken at regions of $\sim 0 \mathrm{~mm}, \sim 1.5 \mathrm{~mm}$ and $\sim 3 \mathrm{~mm}$ from the center. The TEM samples were electropolished using an electrolyte of nitric acid (33\%) and methyl alcohol $(67 \%)$ at a temperature of $243 \mathrm{~K}$. Dual beam focused ion beam/scanning electron microscope (FIB/SEM, FEI 600i) method was used to prepared the TEM specimens of some special positions.

\section{Results}

\subsection{Mechanical properties}

Fig. 1 shows the torque versus twist curves. The torque increases with increasing the torsional angle, and the torque of the $\mathrm{Cu} 30 \mathrm{Zn}$ alloy is higher than that of the $\mathrm{Cu} 10 \mathrm{Zn}$ alloy at the same torsional angle, indicating that $\mathrm{Cu} 30 \mathrm{Zn}$ might have a high strength/hardness due to more effective solid solution strengthening.

Fig. 2 shows the Vicker's hardness of the specimens before and after pre-torsional treatment. The hardness along the radial direction of the as-received sample is homogeneous, and after pre-torsional treatment the hardness is clearly seen to increase along the radial direction. The hardness also increases with increasing the pre-torsional degree. It should be noted that the hardness of $\mathrm{Cu} 30 \mathrm{Zn}$ alloy is higher than that of $\mathrm{Cu} 10 \mathrm{Zn}$ alloy after pre-torsional deformation for the same degree at the same position, which agrees well with the torque during the torsional treatment (shown in Fig. 1). Similar to high pressure torsion (HPT) treatment ${ }^{25}$, the
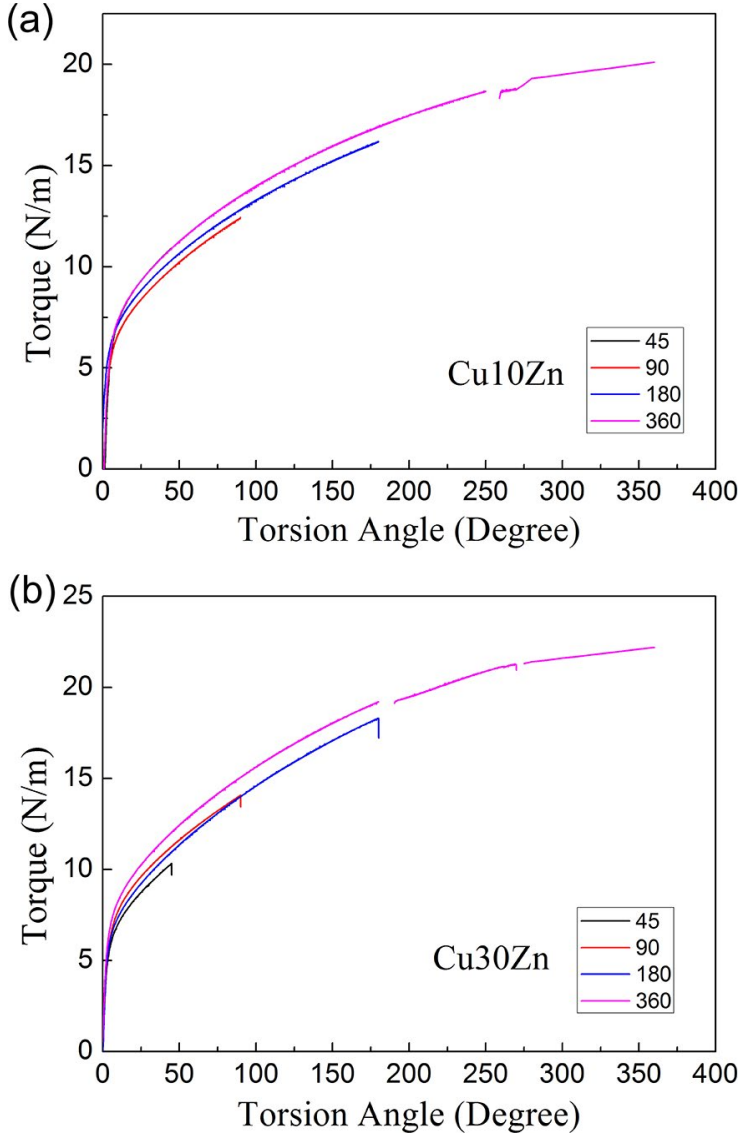

Figure 1. The torque versus torsion angle curves of the $\mathrm{Cu} 10 \mathrm{Zn}$ and $\mathrm{Cu} 30 \mathrm{Zn}$ alloys.

pre-torsional treatment can also introduce gradient strain along the radial direction.

Fig. 3a shows the engineering strain-engineering stress curves of the $\mathrm{Cu} 10 \mathrm{Zn}$ alloy before and after pre-torsional treatment. With increasing the torsional degree, the yield strength and ultimate tensile strength (UTS) of the specimens increase substantially. The yield strength increases from $\sim 220$ $\mathrm{MPa}$ of $\mathrm{Cu} 10 \mathrm{Zn}-0$ sample to $450 \mathrm{MPa}$ of $\mathrm{Cu} 10 \mathrm{Zn}-360$ sample, and the UTS increases from $450 \mathrm{MPa}$ of Cu10Zn-0 sample to $\sim 570 \mathrm{MPa}$ of Cu10Zn-360 sample. For the ductility, the uniform elongation of samples was also changed with the torsional treatment, which is also highly dependent on the torsional degree. Generally, the ductility decreases with increasing the torsional degree, and the reduction of the ductility reaches $\sim 64.5 \%$ after torsional treatment for $360^{\circ}$. Fig. $3 \mathrm{~b}$ shows the engineering strain-engineering stress curves of the $\mathrm{Cu} 30 \mathrm{Zn}$ alloy before and after pre-torsional treatment. The evolutions of yield strength, UTS and ductility of $\mathrm{Cu} 30 \mathrm{Zn}$ alloy after pre-torsional treatment are similar to those of the Cu10Zn alloy. The maximum yield strength and UTS of Cu30Zn-360 sample were $\sim 550 \mathrm{MPa}$ and $\sim 600$ $\mathrm{MPa}$, respectively. The reduction of the ductility is $\sim 71.4 \%$ after torsional treatment for $360^{\circ}$. Fig. $3 \mathrm{c}$ and $3 \mathrm{~d}$ is the corresponding strain hardening rate curves of the $\mathrm{Cu} 10 \mathrm{Zn}$ 

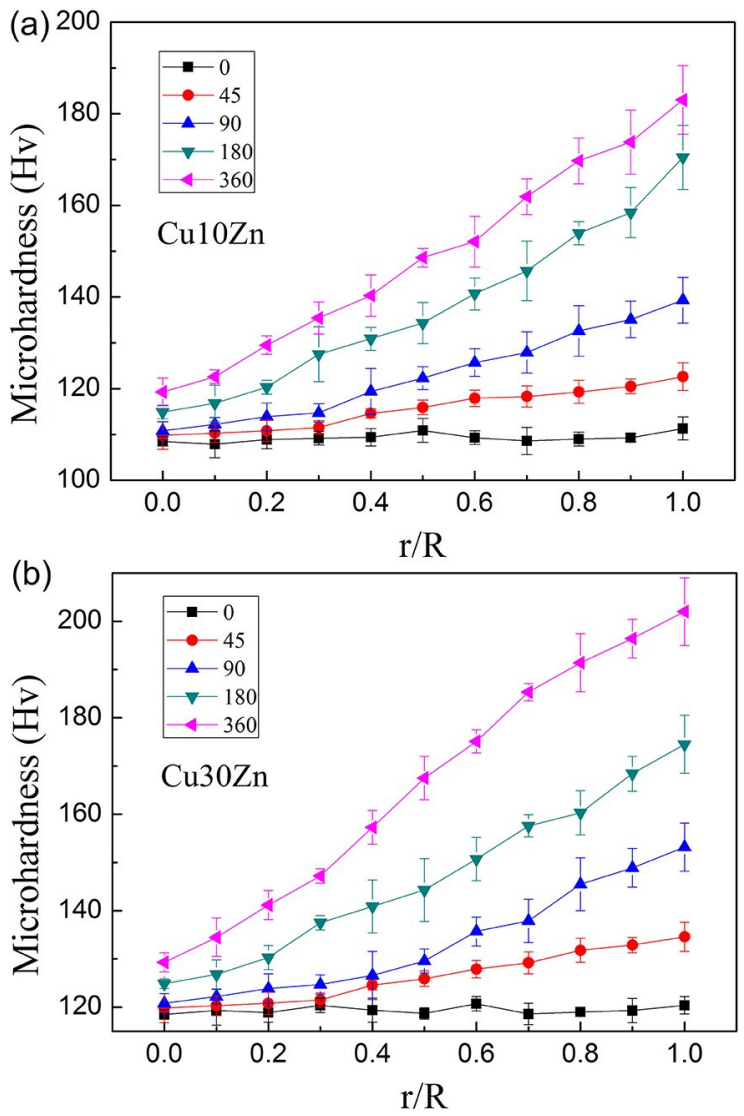

Figure 2. The evolution of the Vicker's hardness of the (a) $\mathrm{Cu} 10 \mathrm{Zn}$ and (b) Cu30Zn alloys before and after pre-torsional treatment.

and Cu30Zn alloys. In the first part of the strain hardening rate curves, the strain hardening rates are very high and drop rapidly due to the formation of a large number of the dislocations tangles all over the interior of the grains. In the second part of the strain hardening rate curves, the strain hardening rates of all the specimens decrease continuously, but decreasing speeds are various and depend significantly on the torsional degree.

\subsection{Microstructural evolution}

Fig. 4 shows the TEM microstructures of the Cu10Zn-180 sample (Fig. 4a-4c) and Cu30Zn-180 sample (Fig. 4d-4f). Here $r / R$ indicates the position from which the EBSD images were obtained ( $R$ is the radius of the cross section of the specimen, $r$ is the radius of the recorded position). It can be seen from Fig. 4a that several dislocations can be observed in the region where $\mathrm{r} / \mathrm{R} \approx 0$ (central region in the specimen) in the Cu10Zn alloy. Because the specimen center where $r / R=0$ was not pre-strained, the structure observed at the specimen center was actually the same as that before torsional treatment. In the region where $\mathrm{r} / \mathrm{R} \approx 0.5$ (see Fig. $4 \mathrm{~b}$ ), profuse dislocations can be observed, the dislocations tangled and formed the dislocation cells. In the region where $\mathrm{r} / \mathrm{R} \approx 1$ (see Fig. $4 \mathrm{c}$ ), dislocation cells, dislocation pile-ups and planar slip can all be observed. For the Cu30Zn-180 specimen, several dislocations can be observed at the center of the specimen (Fig. $4 \mathrm{~d}$ ). In the region where $\mathrm{r} / \mathrm{R} \approx 0.5$ (see Fig. 4e), a large number of the stacking faults (also see the insert image) and dislocations were observed. In the region where $r / R \approx 1$ (see Fig. 4f), some deformation nanotwins can be observed.

\section{Discussion}

It is well known that SFE is an important factor affecting the deformation mechanism of materials. Decreasing SFE can reduce the possibility of cross slip and thus lead to the transition of dislocation slip from wavy slip to planar slip ${ }^{26}$. On the other hand, reducing SFE significantly increases the propensity of deformation twinning, making it a feasible deformation mechanism during deformation ${ }^{27}$. SFE can also significant affect the thickness of the twins, and previous investigation indicated that when the twin boundary spacing is reduced to the nanometer scale, the twin boundary strengthening becomes dominant ${ }^{28}$ and the nanoscale twin boundaries can provide as much strengthening as conventional high-angle grain boundaries via blocking dislocation motion ${ }^{29}$. Previous study indicated that SFE can also affects the formation of incoherent twin boundaries, which lead to the various of split length of $9 \mathrm{R}$ phase ${ }^{30}$. In this paper, $\mathrm{Cu}-10 \mathrm{wt} . \% \mathrm{Zn}$ and $\mathrm{Cu}-30 \mathrm{wt} . \% \mathrm{Zn}$ alloys were treated by the same pre-torsional treatment. After pre-torsional treatment, the microstructures of different positions in the same specimen and the same position in different specimens are various. For the $\mathrm{Cu} 10 \mathrm{Zn}-180$ specimen, in the region where $\mathrm{r} / \mathrm{R} \approx 0.5$ (Fig. $4 \mathrm{~b}$ ) the dislocations slip is wavy slip and dislocation cells were formed. In the region where $\mathrm{r} / \mathrm{R} \approx 1$ (Fig. 4c) the dislocation planar slip can be observed. For the Cu30Zn-180 specimen, in the region where $\mathrm{r} / \mathrm{R} \approx 0.5$ (Fig. 4e) the dislocation planar slip and SFs can be observed. On the other hand, several deformation twins can be observed in the region where $r / R \approx 1$ (Fig. $4 \mathrm{f}$ ). During the torsional processing, the shear strain along the radial direction is gradient ${ }^{15}$, leading to the various microstructure along the radial direction.

For the same material, different deformation processing method can lead to the different twinning capabilities, which will affect the mechanical properties ${ }^{23}$. For Cu- $32 \mathrm{wt} . \% \mathrm{Zn}$, high-pressure torsion (HPT) treatment induced more deformation twins than that of equal-channel angular press (ECAP) treatment, which leads to both higher strength and ductility after HPT treatment ${ }^{23}$. Nanoscale twins promote dislocation-twin-boundaries interactions and create more room for dislocation storage, leading to more pronounced strain hardening. The presence of the nanoscale twins in the grains changes the dislocation activities considerably, since nanoscale twin boundaries not only act as effective barriers for dislocation slip, but also provide space for dislocation 

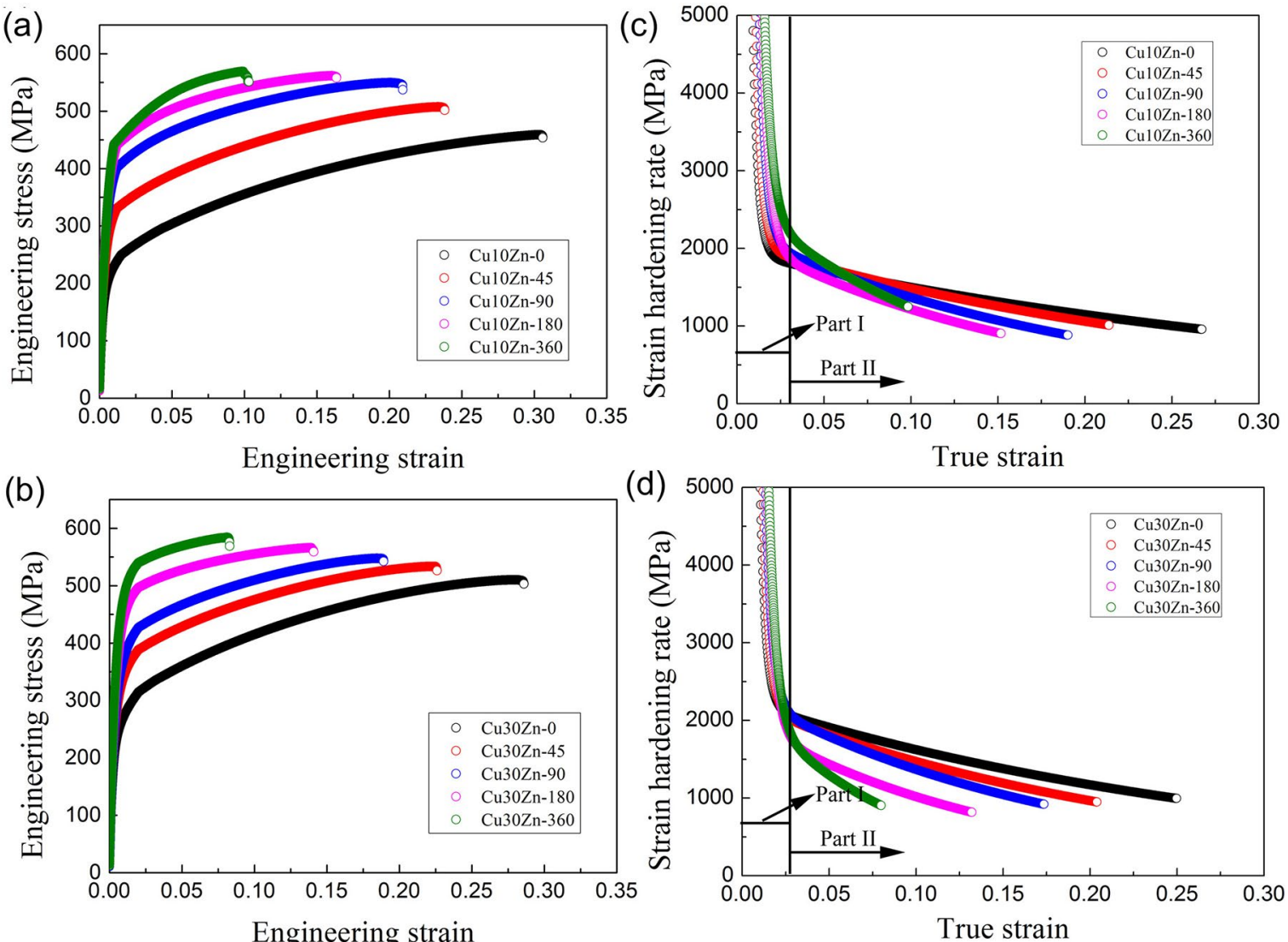

Figure 3. Engineering strain-engineering stress curves of the (a) $\mathrm{Cu} 10 \mathrm{Zn}$ and (b) $\mathrm{Cu} 30 \mathrm{Zn}$ alloys before and after pre-torsional treatment, and the corresponding strain hardening rate curves of (c) Cu10Zn and (d) Cu30 Zn alloys.

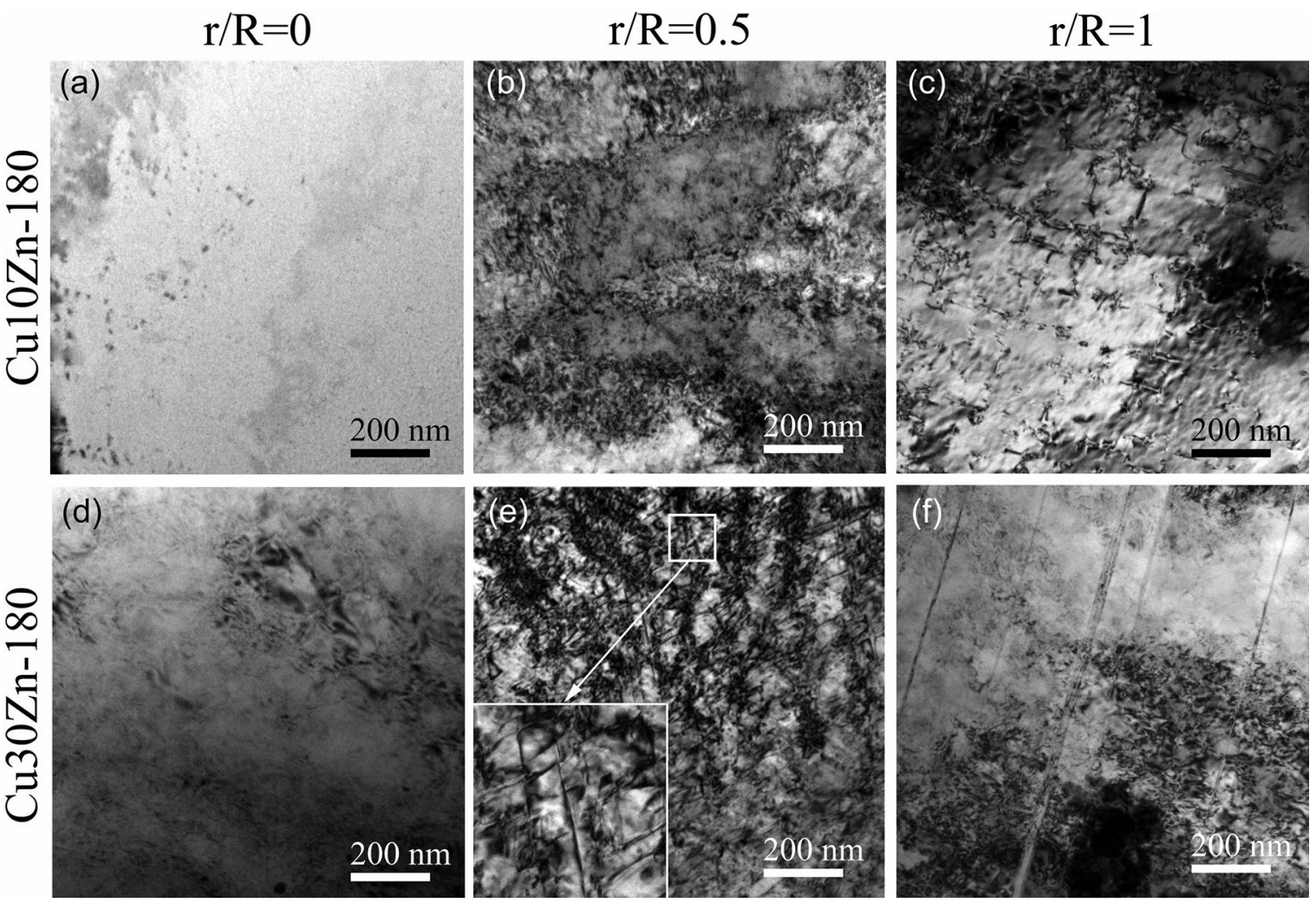

Figure 4. Bright field TEM images of the (a-c) Cu10Zn-180 and (d-f) Cu30Zn-180 specimens at different positions. 
accumulation and storage ${ }^{31,32}$. In this paper, after pre-torsional treatment only several deformation twins were observed in the surface region of Cu-30wt.\%Zn alloy (Fig. 4f). Due to the limit number of the deformation twins, no obvious strain hardening rate improvement was observed in the $\mathrm{Cu}$ 30wt.\%Zn alloy after pre-torsional treatment (Fig. 3d). Thus, the mechanical properties evolutions of both $\mathrm{Cu} 10 \mathrm{Zn}$ and $\mathrm{Cu} 30 \mathrm{Zn}$ alloys after pre-torsional treatment include improved strength but sacrificed ductility, and the evolution tendency for both alloys is the same (Fig. 3a and 3b).

\section{Conclusion}

In the study, $\mathrm{Cu}-10 \mathrm{wt} . \% \mathrm{Zn}$ and $\mathrm{Cu}-30 \mathrm{wt} . \% \mathrm{Zn}$ alloys with different SFEs were treated by pre-torsional deformation. The results showed that after pre-torsional deformation a gradient hardness was formed along the radial direction and the pre-torsional deformation can significantly improve the strength but decrease the ductility of both the $\mathrm{Cu}-10 \mathrm{wt} . \% \mathrm{Zn}$ and $\mathrm{Cu}-30 \mathrm{wt} . \% \mathrm{Zn}$ alloys. After torsional treatment, different microstructures were formed along the radial direction in $\mathrm{Cu}-10 \mathrm{wt} . \% \mathrm{Zn}$ and $\mathrm{Cu}-30 \mathrm{wt} . \% \mathrm{Zn}$ alloys, due to the relative lower SFE of the Cu-30wt.\%Zn alloy compared to that of the $\mathrm{Cu}-10 \mathrm{wt} . \% \mathrm{Zn}$ alloy. The microstructures along the radial direction in $\mathrm{Cu}-30 \mathrm{wt} . \% \mathrm{Zn}$ alloy were "dislocations $\rightarrow$ stacking faults $\rightarrow$ twins (low density)".

\section{Acknowledgements}

The financial supports from the National Natural Science Foundation of China (51771229) and Hunan provincial Innovation Foundation for Postgraduate (CX2017B046) are appreciated.

\section{References}

1. Carrez P, Cordier P. Plastic deformation of materials under pressure. MRS Bulletin. 2017;42(10):714-717.

2. Valiev RZ, Estrin Y, Horita Z, Langdon TG, Zehetbauer MJ, Zhu YT. Producing bulk ultrafine-grained materials by severe plastic deformation. JOM. 2006;58(4):33-39.

3. Valiev RZ, Islamgaliev RK, Alexandrov IV. Bulk nanostructured materials from severe plastic deformation. Progress in Materials Science. 2000;45:103-189.

4. Bridgman PW. Effects of High Shearing Stress Combined With High Hydrostatic Pressure. Physical Review. 1935;48(10):825847.

5. Harai Y, Ito Y, Horita Z. High-pressure torsion using ring specimens. Scripta Materialia. 2008;58(6):469-472.

6. Kawasaki M, Langdon TG. The significance of strain reversals during processing by high-pressure torsion. Materials Science and Engineering: A. 2008;498(1-2):341-348.

7. Koch CC. Optimization of strength and ductility in nanocrystalline and ultrafine grained metals. Scripta Materialia. 2003;49(7):657662.
8. Jia D, Wang YM, Ramesh KT, Ma E, Zhu YT, Valiev RZ. Deformation behavior and plastic instabilities of ultrafinegrained titanium. Applied Physic Letters. 2001;79(5):611-613.

9. Zhu YT, Liao XZ. Retaining ductility. Nature Materials. 2004;3:351-352.

10. Niendorf T, Lotze C, Canadinc D, Frehn A, Maier HJ. The role of monotonic pre-deformation on the fatigue performance of a high-manganese austenitic TWIP steel. Materials Science and Engineering: A. 2009;499(1-2):518-524.

11. Gu J, Song M, Ni S, Liao XZ, Guo SF. Improving the plasticity of bulk metallic glasses via pre-compression below the yield stress. Materials Science and Engineering: A. 2014;602:68-76.

12. Xin YC, Wang MY, Zeng Z, Huang GJ, Liu Q. Tailing the texture of magnesium alloy by twinning deformation to improve the rolling capability. Scripta Materialia. 2011;64(10):986-989.

13. de Oliveira LYS, Siqueira CJM, Fernandes BL, Kuromoto N, Retraint D. Wear behavior of Diamond-like Carbon Deposited on Ti6A14V Prepared with Surface Mechanical Attrition Treatment. Materials Research. 2019;22(2):e20180568.

14. Gu J, Zhang LX, Ni S, Song M. Formation of large scaled zero-strain deformation twins in coarse-grained copper. Scripta Materialia. 2016;125:49-53.

15. Gu J, Zhang LX Ni S, Song M. Effects of grain size on the microstructures and mechanical properties of 304 austenitic steel processed by torsional deformation. Micron. 2018;105:93-97.

16. Wei YJ, Li YQ, Zhu LC, Liu Y, Lei XQ, Wang G, et al. Evading the strength-ductility trade-off dilemma in steel through gradient hierarchical nanotwins. Nature Communications. 2014;5:3580.

17. Guo N, Song B, Guo C, Xin R, Liu Q. Improving tensile and compressive properties of magnesium alloy rods via a simple pre-torsion deformation. Materials \& Design. 2015;83:270275.

18. Guo N, Song B, Yu HB, Xin RL, Wang BS, Liu TT. Enhancing tensile strength of $\mathrm{Cu}$ by introducing gradient microstructures via simple torsion deformation. Materials \& Design. 2016;90:545 550

19. Wang CP, Li FG, Li JH, Dong JZ, Xue FM. Microstructure evolution, hardening and thermal behavior of commercially pure copper subjected to torsion deformation. Materials Science and Engineering: A. 2014;598:7-14.

20. An XH, Wu SD, Wang ZG, Zhang ZF. Enhanced cyclic deformation responses of ultrafine-grained $\mathrm{Cu}$ and nanocrystalline $\mathrm{Cu}-\mathrm{Al}$ alloys. Acta Materialia. 2014;74:200-214.

21. Qu S, An XH, Yang HJ, Huang CX, Yang G, Zang QS, et al. Microstructural evolution and mechanical properties of $\mathrm{Cu}$ $\mathrm{Al}$ alloys subjected to equal channel angular pressing. Acta Materialia. 2009;57(5):1586-1601.

22. Youssef K, Sakaliyska M, Bahmanpour H, Scattergood R, Koch C. Effect of stacking fault energy on mechanical behavior of bulk nanocrystalline $\mathrm{Cu}$ and $\mathrm{Cu}$ alloys. Acta Materialia. 2011;59(14):5758-5764.

23. Zhang P, An XH, Zhang ZJ, Wu SD, Li SX, Zhang ZF, et al. Optimizing strength and ductility of $\mathrm{Cu}-\mathrm{Zn}$ alloys through severe plastic deformation. Scripta Materialia. 2012;67(11):871874. 
24. Wu XX, San XY, Gong YL, Chen LP, Li CJ, Zhu XK. Studies on strength and ductility of $\mathrm{Cu}-\mathrm{Zn}$ alloys by stress relaxation. Materials \& Design. 2013;47:295-299.

25. Langdon TG. Twenty-five years of ultrafine-grained materials: Achieving exceptional properties through grain refinement. Acta Materialia. 2013;61(19):7035-7059.

26. An XH, Qu S, Wu SD, Zhang ZF. Effects of stacking fault energy on the thermal stability and mechanical properties of nanostructured $\mathrm{Cu}-\mathrm{Al}$ alloys during thermal annealing. Journal of Materials Research. 2011;26(3):407-415.

27. An XH, Lin QY, Wu SD, Zhang ZF, Figueiredo RB, Gao N, et al. The influence of stacking fault energy on the mechanical properties of nanostructured $\mathrm{Cu}$ and $\mathrm{Cu}-\mathrm{Al}$ alloys processed by high-pressure torsion. Scripta Materialia. 2011;64(10):954957.
28. Lu K, Lu L, Suresh S. Strengthening Materials by Engineering Coherent Internal Boundaries at the Nanoscale. Science. 2009;324(5925):349-352.

29. Lu L, Chen X, Huang X, Lu K. Revealing the Maximum Strength in Nanotwined Copper. Science. 2009;323(5914):607-610.

30. Gu J, Tang YH, Ni S, Song M. Effect of stacking fault energy on the split length of $9 \mathrm{R}$ phase in coarse-grained $\mathrm{Cu}-\mathrm{Al}$ alloys. Materials Characterization. 2018;142:9-14.

31. Li X, Wei Y, Lu L, Lu K, Gao H. Dislocation nucleation governed softening and maximum strength in nano-twined metals. Nature. 2010;464:877-880

32. Zhu T, Li J, Samanta A, Kim HG, Suresh S. Interfacial plasticity governs strain rate sensitivity and ductility in nanostructured metals. PNAS Proceedings of the National Academy of Science of USA. 2007;104:3031-3036. 